\title{
CYP2D6 Genotype in Relation to Liver Toxicity Due to Tetrabenazine in Iraqi Patients with Hyperkinetic Movement Disorders Zainab A. Abbood ${ }^{*}, 1$, Shatha $\mathrm{H} \mathrm{Ali}^{* * *}$ and Nawfal M Sheaheed ${ }^{* *}$
}

* Department Clinical Pharmacy, College of Pharmacy, University of Baghdad, Baghdad, Iraq. ** Department of Clinical and Laboratory Science, College of Pharmacy, University of Baghdad, Baghdad, Iraq

${ }^{* * *}$ Ministry of Health and Environment, Baghdad Teaching Hospital, Medical City, Baghdad, Iraq.

\section{Abstract}

The common types of movement disorders are; dystonia which is a syndrome of repetitive muscle contractions. While, Huntington disease is autosomal dominant progressive neurodegenerative disorder, which is characterized by involuntary movements ("chorea").

Tetrabenazine therapy has been shown to effectively control these movements compared to placebo. The most commonly reported side effects of tetrabenazine increase liver enzymes and these side effects are dose dependent.

This is a prospective case controlled study was carried on 50 patients whom divided into 2 groups: group 1 involved 25 chorea patients, and group 2 included patients with dystonia, whom treated with (tetrabenazine) for three months. In addition to control group involved 25 healthy subjects to estimate the prevalence of genetic polymorphism of CYP 450 2D6 enzyme in related to tetrabenazine efficacy and toxicity. Blood samples were collected at the beginning to perform a genotyping assay for CYP 450 2D6 enzyme by PCR and to assess liver function and after three months of treatment to assess liver and measuring the plasma concentration of tetrabenazine, alpha and beta dihydrotetrabenazine by HPLC.

The results show a significant CYP 450 2D6 enzyme polymorphism. And elevations of liver enzymes in the patient indicate hepatotoxicity of tetrabenazine and its metabolites.

Keyword:Dystonia, Chorea, Tetrabenazine, Alpha and Beta dihydrotetrabenazine, CYP 4502 D6 Enzyme Polymorphism, Liver Function.

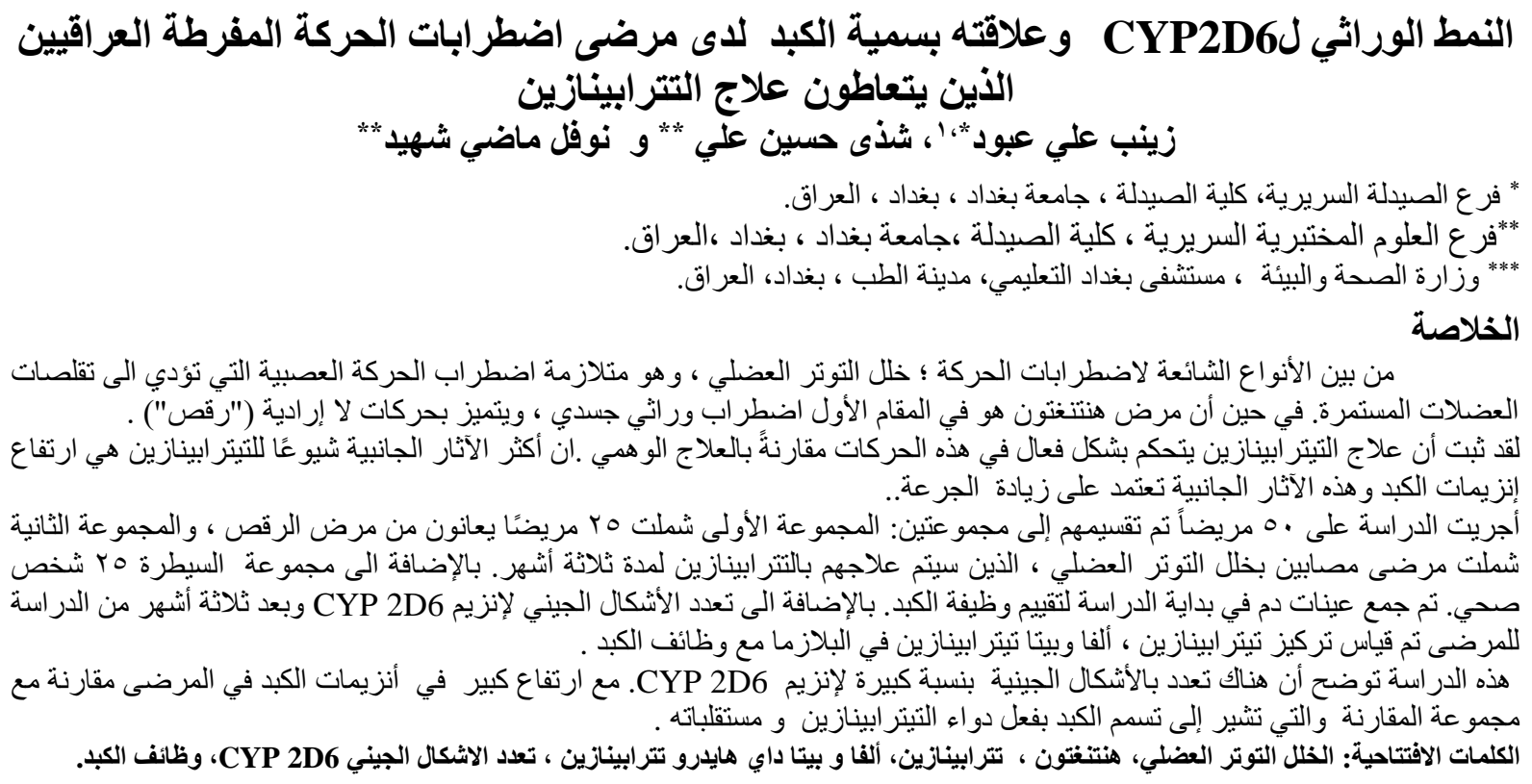

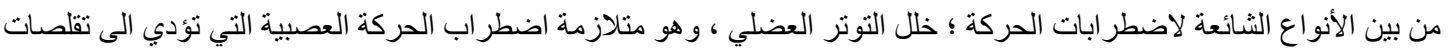

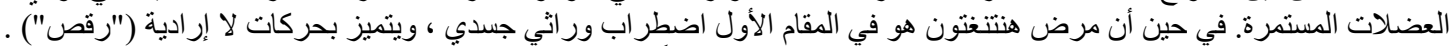

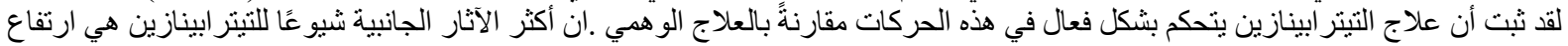

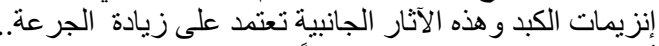

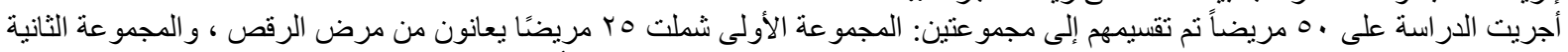

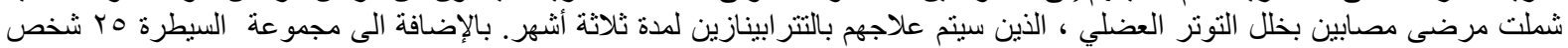

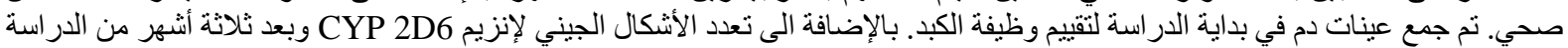

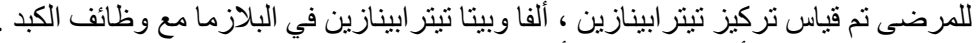

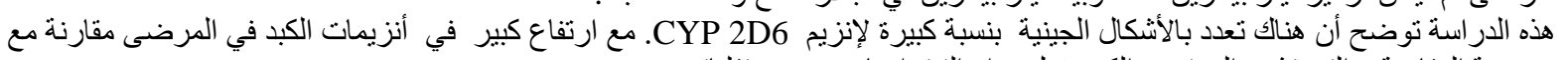

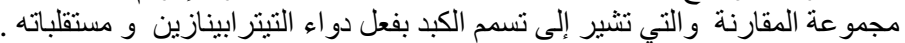

الكلمات الافتتاحية: الخلل التوتر العضلي، هنتنتون ، تترابينازين، ألفاو بيتا داي هايدرو تترابينازين ، تعدد الاشكال الجيني CYP 2D6، وظائف الكبد.

${ }^{1}$ Corresponding author E-mail: zainabaa87@yahoo.com

Received: 28/11/2019

Accepted:15/2/2020

Iraqi Journal of Pharmaceutical Science 


\section{Introduction}

The term "movement disorders" refers to a group of nervous system (neurological) conditions that cause abnormal increase in the movements, which may be voluntary or involuntary $^{(1)}$.Common types of movement disorders include:

Dystonia is a syndrome of neurological movement disorder in which constant or repetitive muscle contractions result in twisting and repetitive movements or abnormal fixed postures ${ }^{(2)}$.Dystonia is often intensified or aggravated by physical activity, and symptoms may progress into adjacent muscles ${ }^{(3)}$

Huntington disease is primarily an adult-onset hereditary autosomal dominant progressive neurodegenerative disorder, which is characterized by involuntary movements ("chorea"), psychiatric symptoms, and cognitive dysfunction that can lead to dementia (4).

Presently, the backbone of treatment for movement disorders is symptomatic and supportive care - no drugs are available to stop or prevent the progression of hyperkinetic movement disorders)5(,)6(. Tetrabenazine therapy (TBZ), a benzoquinoline derivative, is an oral monoamine-depleting agent with selectivity for dopamine. It specially prevents the presynaptic monoamine storage by inhibiting the vesicular monoamine transporter type-2, a presynaptic transporter found mainly in the central nervous system $) 7($, has been shown to effectively control chorea and dystonia symptoms compared with placebo. By using pharmacogenomics, the pharmacotherapy can be optimized, thereby increasing efficacy and decreasing the incidence of adverse events. The Cytochrome P450 (CYP2D6) enzyme metabolizes about $25 \%$ of clinically used drugs for many different drug classes including antidepressants, antipsychotics, antihypertensive, and analgesics. The CYP2D6 is a highly polymorphic gene locus with more than 75 allelic variants, and subjects can be classified into poor metabolizers (PM), intermittent metabolizers (IM), and extensive metabolizers (EM), or ultra-rapid metabolizers $(\mathrm{UM})^{(8,9)}$

Pharmacogenomics, aiming to clarify the relationship between human genome sequence variations and drug responses, has focused on genes whose affecting absorption, distribution, metabolism, and elimination of a given drug (pharmacokinetic pathways), as well as on identifying potential drug targets (pharmacodynamic pathways) )10(.
Pharmacogenetic considerations are particularly relevant to tetrabenazine, as the drug is metabolized via the cytochrome P450 enzyme system (CYP). The two metabolites of tetrabenazine, $\alpha-\mathrm{H}$ - tetrabenazine and $\beta-\mathrm{H}$ tetrabenazine, are metabolized in the liver primarily by CYP2D6 ${ }^{(11)}$.

The most commonly reported side effects of tetrabenazine increase liver enzymes(ALP, ALT, and AST) $)^{(12)}$. Side effects of tetrabenazine are dose dependent.

This study aimed to predicted phenotypes of CYP2D6: poor metabolizers, intermediate metabolizers, and extensive metabolizers or ultra-rapid metabolizers among Iraqi subjects. And to investigate whether CYP2D6 gene polymorphism effect the tetrabenazine, and it is two metabolites :, $\alpha-\mathrm{H}$ - tetrabenazine and $\beta-\mathrm{H}$ tetrabenazine and their relation to liver toxicity.

\section{Patients and Methods}

Patient selection and study design

Fifty movement disorder patients participated in the current prospective case controlled study where divided into 2groups: Group 1 involved 25 patients suffer from chorea (12 males and 13 females) with mean age $41.36 \pm 2.39$ years, and Group 2 includes patients with dystonia (8males and 17 females) with mean age 38.04 2.62 years, treated with (tetrabenazine) for three months. The starting dose of tetrabenazine was $12.5 \mathrm{mg}$ once daily in the morning; titrate up at weekly intervals by $12.5 \mathrm{mg} /$ day; doses of 37.5 to $50 \mathrm{mg}$ was divided into 3 doses. Ethical approval was obtained from the department of clinical pharmacy at the College of the Pharmacy.

The study is carried out in Baghdad medical city during the period from September 2018 to June 2019. Patients undergoing clinical examination by measuring Unified Huntington's Disease Rating Scale (UHDRS) and Unified Dystonia Rating Scale(UDRS) in the movement disorder unit of the hospital as well as in private clinic. Ten millimeter Blood sample were collected at the beginning of the study to measure, liver function tests (serum ALP, AST, and ALT) and genetic polymorphism of CYP 450 2D6 enzyme for both group and after three months of the study to measure the plasma concentration of tetrabenazine, alpha and beta tetrabenazine and liver function tests with the clinical examination for side effects. 


\section{Genotyping of CYP2D6 gene}

After DNA isolation from venous blood by Wizard Genomic DNA purification Kit (Promega,USA). Genotyping of CYP2D6 gene performed by polymerase chain reaction (PCR) conventional (allele specific method) according to method described by Taimour Langaee, Issam Hamadeh, Arlene B. Chapman, et al)13(. The following primers was used for PCR amplification.

1.CYP2D6 *2 (2850 C>T rs16947)

Forward 5' GGCCCCTGCACTGTTTCC 3' Reverse 5' AAGGGGAACCCTGAGAGC 3' 2. CYP2D6 *4 (1846 G>A) rs3892097 Forward 5' TGCCGCCTTCGCCAACCACT 3' Reverse 5' GCAGAGACTCCTCGGTCTCTC 3'

3. CYP2D6 *10 (100 C >T rs1065852)

Forward 5' TGTCCAGAGGAGCCCATTT 3' Reverse 5'GTCGAAGCAGTATGGTGTGTTCT 3' Measure plasma level of tetrabenazine by HPLC

About $(20 \mu 1)$ of patient plasma was injected into the liquid chromatographic system consisting of a $\mathrm{Cl} 8 \mu$ Bondapak column and fluorescence detector. The mobile phase was acetonitrile-1\% acetate buffer, $\mathrm{pH} 4.5$ (50: 50) at a flow-rate of 1_ml/min. The fluorescence of the eluent was quantified using an excitation wave length of $265 \mathrm{~nm}$ and an emission filter (KV418)(14),(15).

Biochemical assay for liver function

Serum ALP level was measured by Cobas c 311 chemistry analyzer made by Roche Diagnostics in cooperation with Hitachi High-Technologies Corporation (16).While serum AST, ALT, and TSB level evaluated using a ready-made kit for this purpose, according to the method of Kirsch JF, et al (17), Kim WR, et al (18), and Kao TW, et al (19) respectively.

Statistical analysis

Data will be analyzed by using SAS (Statistical Analysis System) (version 24.0) program (SPSS Inc., Chicago, Illinois, USA) and Minitab version 17 software. In all comparisons, a p-value $<0.05$ was considered statistically significant.

\section{Results}

Distribution and demographic data of the patients

Fifty patients completed the course of study successfully, there were non-significant differences between all parameters at baseline as shown in (Table 1).

Table 1. Demographic data and baseline characteristics of the patients.

\begin{tabular}{||l|l|l|l||}
\hline Data & Group 1 & Group 2 & P-value \\
\hline Age (yrs.) & $41.36 \pm 2.39$ & $38.04 \pm 2.62$ & 0.468 \\
\hline No. of subjects & 25 & 25 & ------ \\
\hline Gender & $\begin{array}{l}13 \text { females } \\
12 \text { males }\end{array}$ & $\begin{array}{l}17 \text { females } \\
8 \text { males }\end{array}$ & ----- \\
\hline disease Duration(yrs.) & $6.148 \pm 0.599$ & $5.400 \pm 0.580$ & 0.374 \\
\hline BMI & $21.120 \pm 0.590$ & $22.760 \pm 0.751$ & 0.259 \\
\hline Serum Total Bilirubin(mg/dl) & $0.61 \pm 0.052$ & $0.64 \pm 0.060$ & 0.909 \\
\hline Serum Alkaline Phosphatase U/L & $60.03 \pm 3.59$ & $58.26 \pm 4.44$ & 0.570 \\
\hline Serum Aspartate Transaminase U/L & $28.96 \pm 1.49$ & $30.48 \pm 1.70$ & 0.435 \\
\hline Serum Alanine Transaminase U/L & $42.72 \pm 2.05$ & $41.89 \pm 2.17$ & 0.666 \\
\hline
\end{tabular}

Data are expressed as Mean \pm SEM.

\section{Distribution of patients with (CYP $4502 D 6$ gene polymorphism}

Seventy four percent (37) of patients have CYP 450 2D6*2 (normal allele) while
$26 \%$ (13) of patients have allele polymorphisms (CYP 450 2D6*10) . No patients were observed with CYP 450 2D6 *4 polymorphisms in this study(Figure 1). 


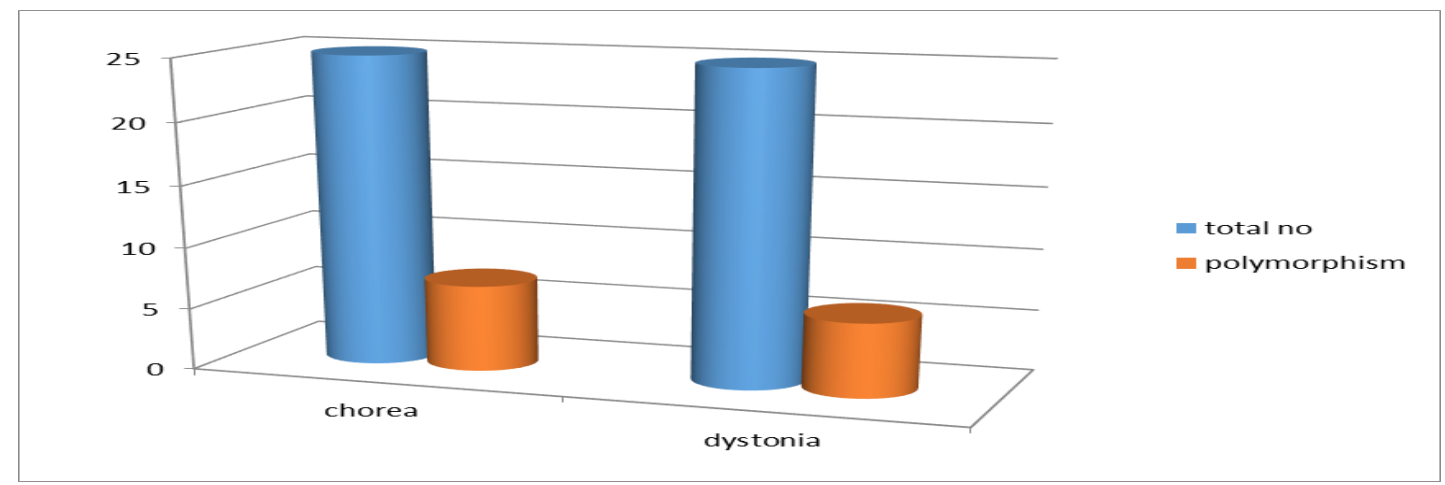

Figure 1. Histogram showing the distribution of patients with (CYP $4502 D 6$ )gene Polymorphism plasma concentration of tetrabenazine, alpha and beta dihydrotetrabenazine for patients with CYP 4502 D6 polymorphism versus the patients without CYP 4502 D6 polymorphism in patients using tetrabenazine:

Tetrabenazine, alpha and beta dihydrotetrabenazine concentration were increased significantly in the patients with CYP 450 2D6*10 polymorphisms compared to patients with CYP $450 \quad 2 \mathrm{D} 6 * 2$ using tetrabenazine in chorea and dystonia (Figure 2, 3)

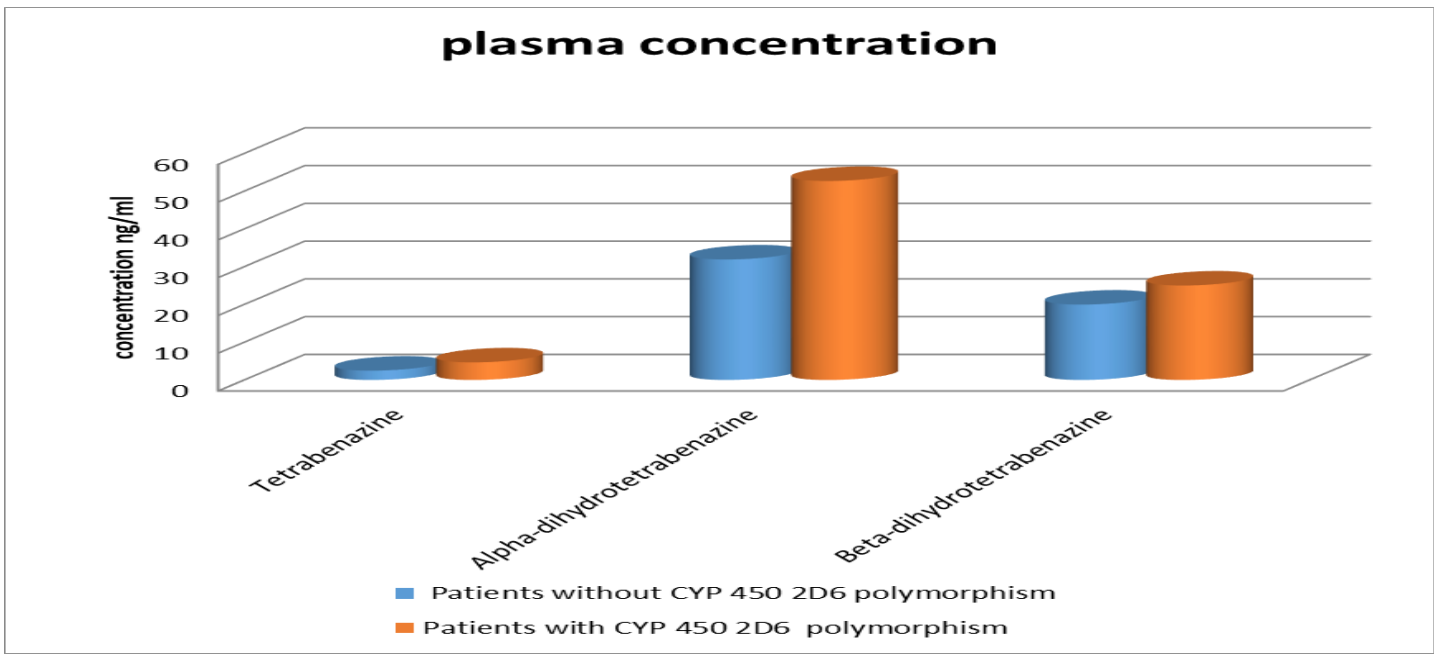

Figure 2. plasma concentration of tetrabenazine, alpha and beta dihydrotetrabenazine for patients with CYP $4502 D 6$ polymorphism versus the patients without CYP 450 $2 D 6$ polymorphism in chorea patients using tetrabenazine.

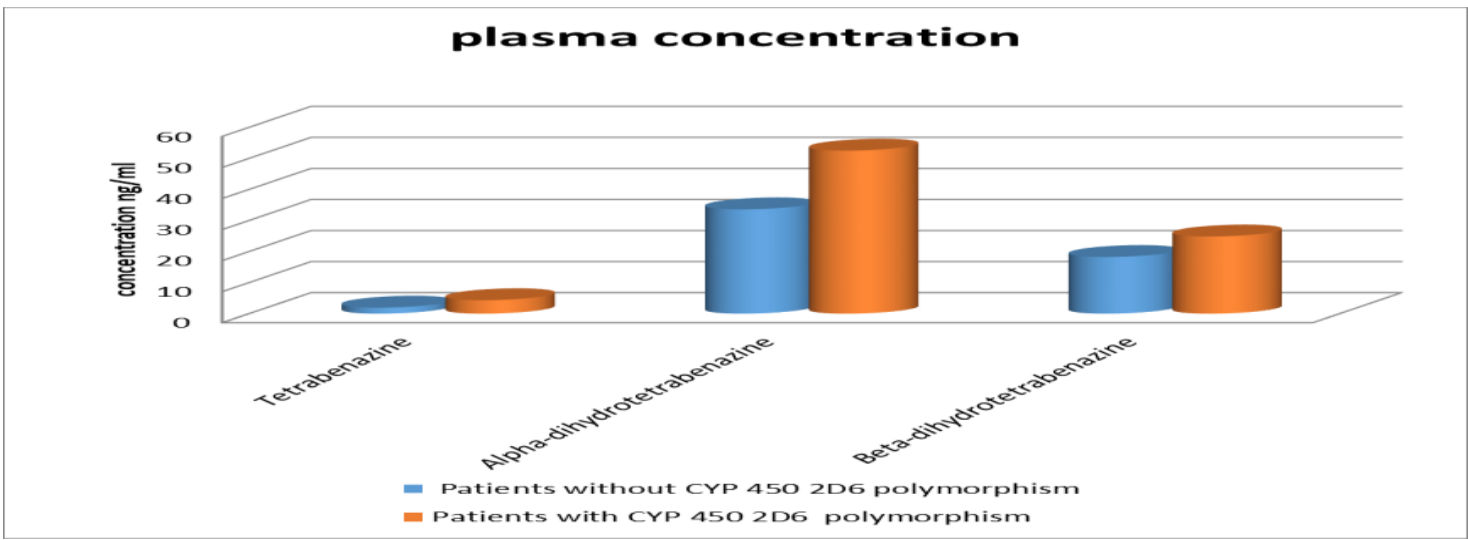

Figure 3. Plasma concentration of tetrabenazine, alpha and beta dihydrotetrabenazine for patients with CYP $4502 D 6$ polymorphism versus the patients without CYP $4502 D 6$ polymorphism in dystonia patients using tetrabenazine. 
Effect of tetrabenazine on liver enzymes

Patients was subdivided into $\mathrm{A}$ subgroup (patients with normal allele and B subgroup (patients with allele polymorphism).There was a non-significant difference in serum Alkaline Phosphatase (ALP), Alanine Transaminase (ALT), Aspartate Transaminase (AST), and total bilirubin (TSB) among treated subgroups at pretreatment. While after three months of treatment with tetrabenazine, the study showed that was a significant elevated in serum ALP, ALT, and AST while non-significant difference TSB in both subgroup A and B compared to subgroups at pretreatment, which is highly increased in liver enzymes in subgroup B as showed in ( Table 2).

Table 2. Effect of tetrabenazine on liver enzymes in patients with chorea and dystonia after three months of treatment.

\begin{tabular}{|c|c|c|c|c|c|c|c|}
\hline \multicolumn{2}{|c|}{ Liver Enzyme } & \multicolumn{2}{|c|}{ Chorea } & \multirow{2}{*}{$\begin{array}{l}\text { P- } \\
\text { value }\end{array}$} & \multicolumn{2}{|c|}{ Dystonia } & \multirow[t]{2}{*}{$\overline{P \text { P-value }}$} \\
\hline & & Pretreatment & $\begin{array}{l}\text { After } \\
\text { treatment }\end{array}$ & & Pretreatment & $\begin{array}{l}\text { After } \\
\text { treatment }\end{array}$ & \\
\hline \multirow{2}{*}{$\begin{array}{l}\text { ALP } \\
(\mathrm{U} / \mathrm{L})\end{array}$} & $\mathrm{A}$ & $63.93 \pm 4.09$ & $80.11 \pm 4.71$ & $0.014^{*}$ & $59.35 \pm 5.36$ & $74.02 \pm 4.67 *$ & $0.047^{*}$ \\
\hline & $\mathrm{B}$ & $49.99 \pm 6.25$ & $98.57 \pm 7.53$ & $0.001 *$ & $54.80 \pm 7.93$ & $91.67 \pm 5.75^{*}$ & $0.004 *$ \\
\hline \multirow{2}{*}{$\begin{array}{l}\text { ALT } \\
(\mathrm{U} / \mathrm{L})\end{array}$} & $\mathrm{A}$ & $44.02 \pm 2.58$ & $50.92 \pm 2.18$ & $0.049 *$ & $42.99 \pm 2.58$ & $54.55 \pm 3.08$ & $0.007 *$ \\
\hline & $\mathrm{B}$ & $39.40 \pm 2.95$ & $61.74 \pm 4.22$ & $0.001 *$ & $38.40 \pm 3.87$ & $67.55 \pm 4.77$ & $0.001 *$ \\
\hline \multirow{2}{*}{$\begin{array}{l}\text { AST } \\
(\mathrm{U} / \mathrm{L})\end{array}$} & $\mathrm{A}$ & $29.50 \pm 1.63$ & $33.72 \pm 1.17$ & $0.045^{*}$ & $29.95 \pm 1.83$ & $39.47 \pm 1.89$ & $0.001^{*}$ \\
\hline & $\mathrm{B}$ & $27.57 \pm 3.46$ & $39.86 \pm 2.35$ & $0.015^{*}$ & $32.17 \pm 4.35$ & $52.50 \pm 3.45$ & $0.005^{*}$ \\
\hline \multirow{2}{*}{$\begin{array}{c}\text { TSB } \\
(\mathrm{mg} / \mathrm{dl})\end{array}$} & $\mathrm{A}$ & $0.594 \pm 0.06$ & $0.557 \pm 0.033$ & 0.583 & $0.658 \pm 0.08$ & $0.679 \pm 0.06$ & 0.826 \\
\hline & $\mathrm{B}$ & $0.643 \pm 0.11$ & $0.614 \pm 0.059$ & 0.820 & $0.567 \pm 0.08$ & $0.5833 \pm 0.06$ & 0.876 \\
\hline
\end{tabular}

Data are expressed as Mean \pm SEM; ;*significantly difference compare to pretreatment within the same group ( $p<0.05)$. A (patients with normal CYP 450 2D6 gene) and B (patients with CYP 450 2D6 polymorphism).

The correlation of plasma concentration of alpha dihydrotetrabenazine and plasma concentration of tetrabenazine with liver enzymes (ALP, AST, ALT, and TSB) in patients group:

The study showed a significant correlation between tetrabenazine and alpha dihydrotetrabenazine plasma concentrations and serum AST (Figure 4) and ALT (Figure 5) and (Figure 6) . the ALP, and TSB serum concentration and was non-significant with serum ALP and TSB as in (Table 3) in chorea patients

Table 3. Summarizes the relationship between tetrabenazine and alpha dihydrotetrabenazine plasma concentration and serum concentration of ALP, AST, ALT, and TSB in chorea patients.

\begin{tabular}{|l|l|l|l|l|l||}
\hline \hline Concentration & ALP & AST & ALT & TSB \\
\hline \multirow{3}{*}{ TBZ } & R_value & 0.344 & 0.399 & 0.591 & 0.173 \\
\cline { 2 - 6 } & P_value & 0.092 & $0.048^{*}$ & $0.002^{*}$ & 0.409 \\
\hline \multirow{2}{*}{ Alpha DTBZ } & R_value & 0.303 & 0.343 & 0.599 & 0.189 \\
\cline { 2 - 6 } & P_value & 0.141 & 0.093 & $0.002^{*}$ & 0.366 \\
\hline
\end{tabular}

* Significant difference 


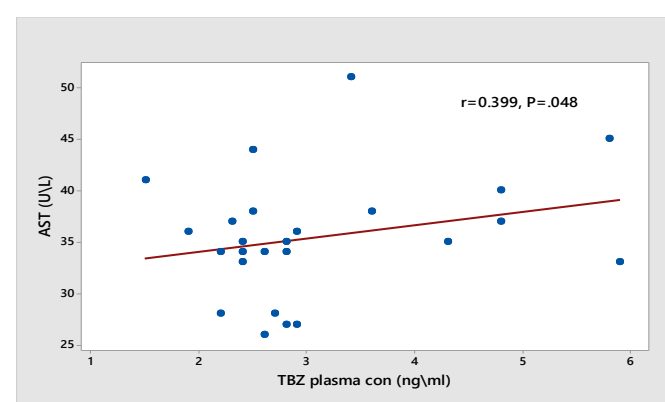

Figure 4. Plasma concentration of tetrabenazine related to serum AST in chorea patients.

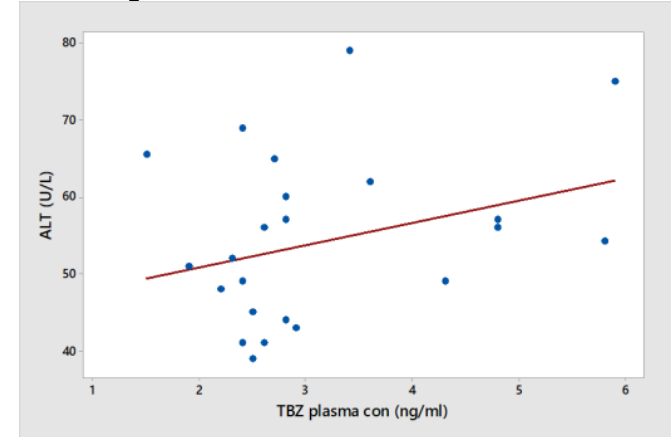

Figure 5. Plasma concentration of tetrabenazine related to serum ALT in chorea patients.

Table 4. Summarizes the relationship between tetrabenazine and alpha dihydrotetrabenazine plasma concentration and serum concentration of ALP, AST, ALT, and TSB in dystonia patients.

\begin{tabular}{||l|l|l|l|l|l||}
\hline \hline Concentration & ALP & AST & ALT & TSB \\
\hline \multirow{2}{*}{ ABZ } & R_value & 0.210 & 0.460 & 0.430 & -0.158 \\
\cline { 2 - 6 } & P_value & 0.314 & $0.021 *$ & $0.032 *$ & 0.450 \\
\cline { 2 - 6 } & R_value & 0.235 & 0.288 & 0.249 & -0.108 \\
\cline { 2 - 6 } & P_value & 0.259 & 0.162 & 0.230 & 0.609 \\
\hline \hline
\end{tabular}

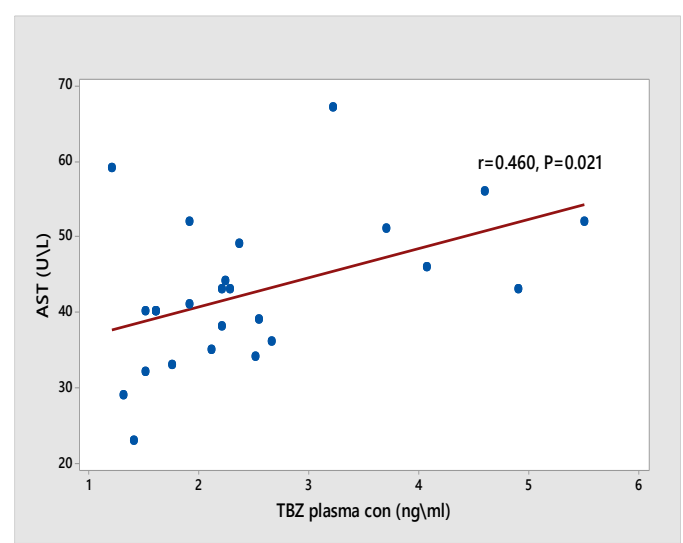

Figure 7. Plasma concentration of tetrabenazine related to serum AST in dystonia patients.

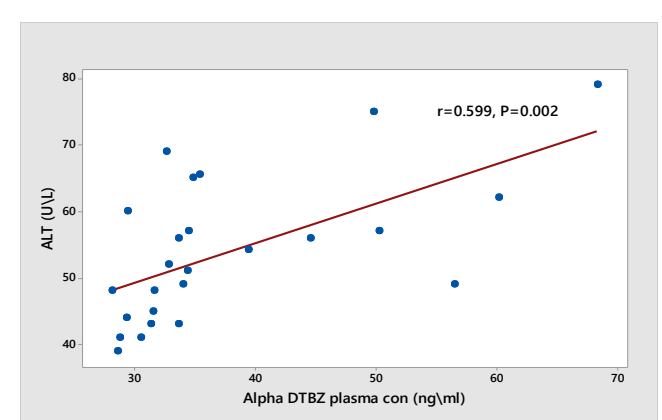

Figure 6. Plasma concentration of alpha dihydrotetrabenazine related to serum ALT in chorea patients.

While in dystonia the study showed a non-significant correlation between tetrabenazine and alpha dihydrotetrabenazine plasma concentrations and the ALP, AST, and TSB serum concentration and only was significant between the tetrabenazine plasma concentrations and serum AST and ALT as in (Table 4) and (Figure 7,8) . 


\section{Discussion}

Distribution of patients with (CYP $4502 D 6$ ) gene polymorphism

Figure (1) shows that the number (percentage) of patients with CYP 450 2D6*2 was 37 (74\%), whereas, patients with CYP 450 2D6 *10 was $13(26 \%)$. No patients were observed with CYP 4502 D6 $* 4$ polymorphisms in this study. To avoid tetrabenazine side effects, genotyping tests before the initiation of therapy could identify patients with unacceptable mortality and morbidity risks. The CYP2D6 activity ranges considerably within a population and includes ultrarapid metabolizers (UMs), extensive metabolizers (EMs), intermediate metabolizers (IMs) and poor metabolizers (PMs). The allele $* 10$ give rise to substrate-dependent decreased activity. It is clear that alleles $* 3, * 4, * 5, * 6$ and $* 7$ have no enzyme activity ${ }^{(20)}$.

No patients were observed with CYP 450 2D6 *4 polymorphisms in this study.

plasma concentration tetrabenazine, Alpha and Beta dihydrotetrabenazine for all patients:

There has been promoting from monitoring a drug level in plasma of tetrabenazine and its metabolites for hyperkinetic movement disorders and take with precaution in the polymorphism of CYP 450 2D6 enzyme. The plasma concentration of tetrabenazine after one and half hour for therapeutic efficacy suggested as less than 2.5 $\mathrm{ng} / \mathrm{ml}$ and Alpha and Beta dihydrotetrabenazine $40.5 \mathrm{ng} / \mathrm{ml}$ and $25.7 \mathrm{ng} / \mathrm{ml}$ respectively ${ }^{(21)}$.

Tetrabenazine is rapidly metabolized via first-pass metabolism into two main metabolites known as alpha and betadihydrotetrabenazine (DTBZ). Of these two compounds, alpha-DTBZ is pharmacologically active, whereas beta-DTBZ is pharmacologically inert. Peak plasma concentrations of alpha-DTBZ and beta-DTBZ are achieved within one to 1.5 hours following an oral dose, and these compounds have a halflife of approximately 10 hours. In contrast, TBZ exhibits a half-life of about six hours. DTBZ is further metabolized by CYP2D6 to Odealkylated DTBZ, which is subsequently excreted via the urine and feces. The metabolites are primarily renal eliminated ${ }^{(22)}$.

There was a significant increase in plasma concentration of alpha and betadihydrotetrabenazine in patients with CYP2D6 polymorphism in comparison with those with non_mutant gene-phenotype that is due to the

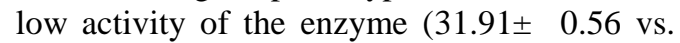
$52.69 \pm 3.7)(19.96 \pm 0.34$ vs. $25.01 \pm 0.97)$

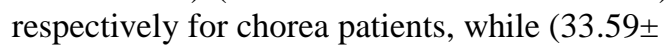

0.58 vs. $52.5 \pm 4.7)(18.25 \pm 0.87$ vs. $24.85 \pm$ 1.1) for dystonia patients, which results in elevation in the plasma concentration of tetrabenazine $(2.467 \pm 0.086 \mathrm{ng} / \mathrm{ml}$ vs. $4.657 \pm$ $0.37)$ for chorea and (1.932 \pm 0.10 vs. $4.325 \pm 0.34$ ) for dystonia .

\section{Effect of tetrabenazine on liver enzymes}

The results regarding ALP, ALT, and AST as shown in (Table 2) indicate that a significant elevation in liver enzymes in both groups. Moreover, a non-significant difference in serum TB among groups post-treatment.

The present results indicate that a highly significant effect in both subgroup A and $\mathrm{B}$ of both group compared to pretreatment, and statistically significant difference observed after three months between subgroups this increment in groups B related to CYP 450 2D6 polymorphism which lead to increase the drug concentrations.

In this study, highly significant elevations of liver enzymes in the patients compared to pretreatment, indicating hepatotoxicity..

A positive non-significant correlation between tetrabenazine plasma concentrations and ALP in both chorea and dystonia were observed, while it was significantly correlated with ALT and AST in both chorea and dystonia. Regarding alpha dihydrotetrabenazine concentration, a (positive) non-significant correlation was found with ALP, ALT, and AST in both groups.

Consequently, there was no significant correlations were detected between plasma concentrations of tetrabenazine and alpha DTBZ levels and TSB level in both chorea and dystonia

\section{Conclusions}

According to the data of the present study, we can conclude that:

1. There was high incidence (26\%) of CYP 450 2D6 gene polymorphisms in Iraqi patients with movement disorders and mainly CYP 450 $2 \mathrm{D} 6 * 10$ which is intermediate metabolizers (IMs) .

2. Higher plasma concentration of tetrabenazine among patient with CYP 450 2D6*10 polymorphism in comparison with patient without CYP 450 2D6 polymorphism.

3. Positive significant correlations were detected between serum levels of tetrabenazine and its metabolites with liver function parameters indicating hepatic toxicity due to tetrabenazine metabolites. 


\section{Acknowledgement}

The present work was abstracted from $\mathrm{PhD}$ thesis submitted to the Department of Clinical Pharmacy, College of Pharmacy, University of Baghdad. The authors are greatly thankful to Baghdad Teaching Hospital, Medical City and AL-Zahraa Teaching Hospital for supporting this project.

\section{Reference}

1. Fahn S, Jankovic J. Principal \& Practice of Movement Disorders,1st ed., Churchill Livingstone, Elsevier, Philadelphia, USA; 2007:p. 1-652.

2. "Dystonias Fact Sheet - National Institute of Neurological Disorders and Stroke". Archived from the original on 23 April 2018.

3. Balint B, Bhatia KP. Dystonia: an update on phenomenology, classification, pathogenesis and treatment. Current opinion in neurology. 2014;27(4):468-476.

4. Samuel Frank. Treatment of Huntington's Disease. Neurotherapeutics. 2014; 11(1): 153-160.

5. Frank S, Jankovic J. "Advances in the pharmacological management of Huntington's disease". Drugs.2010; 70 (5): 561-571.

6. Jankovic J. Medical treatment of dystonia. Movement Disorders. 2013;28(7):10011012.

7. Pettibone DJ, Pflueger AB, Totaro JA. Tetrabenazine-induced depletion of brain monoamines: mechanism by which desmethylimipramine protects cortical norepinephrine. European journal of pharmacology. 1984;102(3-4):431-436.

8. Ingelman-Sundberg M, Sim SC, Gomez $\mathrm{A}$, et al. Influence of cytochrome P450 polymorphisms on drug therapies: pharmacogenetic, pharmacoepigenetic and clinical aspects. Pharmacol Ther. 2007;116(3):496-526 .

9. Kwong EH. A novel genotyping algorithm for the CYP2D6* 10 allele in Asians using real-time, rapid-cycle PCR and multiplex PCR (Doctoral dissertation, University of British Columbia).

10. Chan A, Pirmohamed M, Comabella M. Pharmacogenomics in neurology: current state and future steps. Annals of neurology. 2011;70(5):684-697.
11. Jankovic J, Clarence-Smith K. Tetrabenazine for the treatment of chorea and other hyperkinetic movement disorders. Expert Review of Neurotherapeutics. $2011 ; 11$ (11) :1509 1523.

12. Scott, L. J. Tetrabenazine. CNS drugs. 2011; 25(12): 1073-1085.

13. Whyte, M. P., Kempa, L. G., McAlister, W. H., et al. Elevated serum lactate dehydrogenase isoenzymes and aspartate transaminase distinguish AlbersSchönberg disease (chloride channel 7 deficiency osteopetrosis) among the sclerosing bone disorders. Journal of Bone and Mineral Research.2010; 25(11):25152526.

14. Langaee, T., Hamadeh, I., Chapman, A. B., et al. A novel simple method for determining CYP2D6 gene copy number and identifying allele (s) with duplication/multiplication. PLoS One, 2015; 10(1), e0113808.

15. Mehvar R, Jamali F. Concentration-effect relationships of tetrabenazine and dihydrotetrabenazine in the rat. Journal of pharmaceutical sciences. 1987;76(6):461465.

16. Ramazani A, Rezaei M, Rouhani M. An Applicable Method for the Estimation of Tetrabenazine by Simple RP-HPLC in Tablet Dosage Form. Chemical Methodologies. 2017 Oct 1;1:136-44.

17. Patton C. J, Crouch S .R. Spectrophotometric and kinetics investigation of Berthelot reaction for the determination of ammonia . Annual. Chem 1977; 49(3):464-469

18. Kirsch JF, Eichele G, Ford GC, et al. Mechanism of action of aspartate aminotransferase proposed on the basis of its spatial structure. Journal of molecular biology. 1984;174(3):497-525.

19. Kim WR, Flamm SL, Di Bisceglie AM, Bodenheimer HC. Serum activity of alanine aminotransferase (ALT) as an indicator of health and disease. Hepatology. 2008 ;47(4):1363-1370. 
20. Kao TW, Chou $\mathrm{CH}$, Wang $\mathrm{CC}$, et al. Associations between serum total bilirubin levels and functional dependence in the elderly. Internal medicine journal. 2012;42(11):1199-1207.

21. Shu-Feng Zhou. Polymorphism of Human Cytochrome P450 2D6 and Its Clinical Significance Part II. Clinical Pharmacokinetics. 2009; 48(12): 761-804.
22. Scherman D, Jaudon P, Henry JP. Characterization of the monoamine carrier of chromaffin granule membrane by binding of $[2-3 \mathrm{H}]$ dihydrotetrabenazine. Proceedings of the National Academy of Sciences. 1987;80(2):584-8.

23. Kenney C, Jankovic J. Tetrabenazine in the treatment of hyperkinetic movement disorders. Expert Review of Neurotherapeutics. 2006;6:7-17.

Baghdad Iraqi Journal Pharmaceutical Sciences by bijps is licensed under a Creative Commons Attribution 4.0 International License. Copyrights@ 2015 College of Pharmacy - University of Baghdad. 